\title{
Dependences between the footwear fitting and feet structure in girls of third-grade primary school
}

Authors' Contribution: A Study Design

B Data Collection

C Statistical Analysis

D Data Interpretation

E Manuscript Preparation

F Literature Search

G Funds Collection

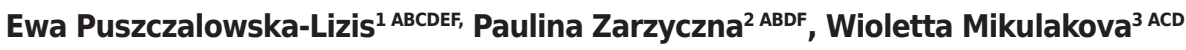 \\ ${ }^{1}$ Medical College, Institute of Health Sciences, University of Rzeszow, Rzeszow, Poland \\ ${ }^{2}$ Center of Physical Rehabilitation „Tutmed”, Non Public Health Care Institution, \\ Sanok, Poland \\ ${ }^{3}$ Faculty of Health Care, Department of Physiotherapy, University of Presov, \\ Presov, Slovakia
}

\section{abstract}

Background: The study aimed to study dependences between the footwear fitting and feet structure in girls of third grade of primary school.

Material and methods: The research tool was the podoscope CQ-ST. The footwear fitting to the feet of the examined children was tested using the Clevermess device.

Results: Statistically significant relationships between the frequency of varus deformity of the Vth toe of the right foot and the width fitting of the outdoor footwear were found $(p=0.027)$. Statistically significant relationships between the length of the indoor footwear and the heel angle $(\gamma)$ of the left foot have also been noted $(p=0.038)$.

Conclusions: Conclusions: Children with a wider forefoot wear longer shoes, which is why there is a need to take into account differences in the foot width in the production of footwear used indoors. The use of too short footwear, without free space that is necessary for the proper setting of the foot during movement or load, is a factor leading to excessive lateral arching. Wearing too wide shoes affects the formation of varus deformity of the Vth toe of the right foot.

Key words: foot deformities, footwear, fit.

\section{article details}

Article statistics: Word count: 3,544; Tables: 5; Figures: 0; References: 26

Received: May 2020; Accepted: June 2020; Published: September 2020

Full-text PDF: http://www.balticsportscience.com

Copyright @ Gdansk University of Physical Education and Sport, Poland

Indexation: Celdes, Clarivate Analytics Emerging Sources Citation Index (ESCI), CNKI Scholar (China National Knowledge Infrastructure), CNPIEC, De Gruyter - IBR (International Bibliography of Reviews of Scholarly Literature in the Humanities and Social Sciences), De Gruyter - IBZ (International Bibliography of Periodical Literature in the Humanities and Social Sciences), DOAJ, EBSCO - Central \& Eastern European Academic Source, EBSCO - SPORTDiscus, EBSCO Discovery Service, Google Scholar, Index Copernicus, J-Gate, Naviga (Softweco, Primo Central (ExLibris), ProQuest - Family Health, ProQuest - Health \& Medical Complete, ProQuest - Illustrata: Health Sciences, ProQuest - Nursing \& Allied Health Source, Summon (Serials Solutions/ProQuest, TDOne (TDNet), Ulrich's Periodicals Directory/ulrichsweb, WorldCat (OCLC)

Funding: This research received no specific grant from any funding agency in the public, commercial, or not-for-profit sectors.

Conflict of interests: Authors have declared that no competing interest exists.

Corresponding author: Dr hab. Ewa Puszczalowska-Lizis; Medical College, Institute of Health Sciences, University of Rzeszow, Warzywna 1A Street, 35-959 Rzeszow, Poland; e-mail: ewalizis@poczta.onet.pl.

Open Access License: This is an open access article distributed under the terms of the Creative Commons Attribution-Non-Commercial-NoDerivatives 4.0 International (https://creativecommons.org/licenses/by-nc-nd/4.0/), which permits use, distribution and reproduction in any medium, provided the original work is properly cited, the use is non-commercial and is otherwise in compliance with the license. 


\section{INTRODUCTION}

Human foot is an important static-dynamic part of the motor system. It supports the mass of the whole body, and in static conditions it enables balancing of the body's spatial position. On the other hand, it is a propelling mechanism giving the body propulsion while moving [1-3].

On the basis of the available scientific references it could be started that feet disorders are a source of problems in everyday life. They can have a negative effect on the efficiency and condition of the higher parts of the kinematic chain. Therefore, the prevention of foot deformities is particularly important in this respect. It should primarily be based on their care, hygiene and appropriate selection of footwear [4-9].

According to Wolf et al. [10], the type of footwear worn can affect the shape of the foot, changing its natural movement during locomotion. The authors found that light, flexible footwear supports the development of feet. However, wearing wrongly fitted shoes - too short, too tight and stiff, especially in childhood, leads to their deformation. According to the authors, most of the deformations arise due to the use of improperly chosen full footwear, and much less often due to wearing inappropriately fitted sandals or slippers. Walther et al. [11] emphasized that girls' feet are more often deformed due to their structure that is more delicate. Wang et al. [12] pointed to the need for manufacturers to care for the ergonomics of footwear. Designing footwear requires knowledge of issues related to skeletal development processes in the early stages of ontogenesis, including the dynamics of changes in the shape of the child's foot. Correctly made footwear should be light and have a proper shape of the front part. The top of the shoe cannot compress the dorsal part of the foot. The adequate height and width of the so-called "shoetoe" should provide the toes with correct setting on the one hand, and allow free movement on the other hand. The shoe should fulfill the task of stabilizing the foot, not limiting its physiological movements and not compressing. Wearing too narrow shoes causes pressure on the toes and subsequent deformation, and also hinders the work of the muscles and affects the stretching of the ligaments that maintain the transverse arch. The size of the shoe should be adjusted accordingly to the length of the foot. Therefore, when buying children's shoes, one should take into account the so-called functional surplus, which is a reserve for the increase in the length of the foot during the period of use and secures the free space in the footwear needed to lengthen the longitudinal arch (the so-called apparent increase in the length of the foot) during movement or load. The functional excess should take into account the size of the mean foot growth in the period from 6 to 12 months. In Poland, the current PN-87/0-91055 standard (Size of Shoe Lasts) for children under 15 provides for a functional surplus of $10 \mathrm{~mm}$, which is the difference between the length of the foot and the inner length of the footwear [13, 14].

The analysis of extensive literature indicates that the footwear fitting in relation to the developing foot is the issue with a limited range of empirical studies. This was the reason for undertaking the subject of the paper which aim was to examine dependences between the footwear fitting and feet structure in girls of third grade primary school.

The following research questions have been formulated:

1. Are there any dependencies between the lengthwise fit of indoor and outdoor shoes and the incidence of foot deformities in girls aged 9?

2. Are there any dependencies between the widthwise fit of indoor and outdoor shoes and the incidence of foot deformities in girls aged 9? 


\section{MATERIAL AND METHODS}

The study comprised 100 9-year-old girls attending randomly selected schools in the Sanok administrative district. The selected group was subsequently verified in terms of its compliance with pertinent inclusion and exclusion criteria. The inclusion criteria were as follows: age 9 years; lack of any diseases and/or injuries of the musculoskeletal system; lower limbs with no previous surgical interventions, including feet; no genetically dependent hallux valgus, as confirmed in an interview. The exclusion criteria as follows: not understanding the instructions that were necessary for the measurement procedures, refusal to participate in the trial.

The mean body mass of the examined girls was $\overline{\mathrm{x}}=30.42 \pm 6.80 \mathrm{~kg}$, the mean body height was $\overline{\mathrm{x}}=132.88 \pm 6.32 \mathrm{~cm}$, while the average BMI amounted to $\overline{\mathrm{x}}=17.09 \pm 2.82$.

The research tool was the podoscope CQ-ST (Electronic System). The study entailed measuring of the plantar feet surfaces in a relaxed stance, with the upper limbs hanging along the body. Each time, both feet were subjected to examination. The width and foot angle were natural, unforced. The following parameters were measured: foot length $[\mathrm{cm}]$, foot width [cm], Clarke's angle $\left[{ }^{\circ}\right]$ - longitudinal foot arch, heel angle $(\gamma)\left[^{\circ}\right]$ - transverse foot arch, hallux valgus angle $(\alpha)\left[^{\circ}\right]$, the angle of the varus deformity of the Vth toe $(\beta)$, in ${ }^{\circ}[15-19]$.

The footwear that the children wore to school (outdoor footwear) and shoes worn at school (indoor footwear) were examined. The typical outdoor shoes for schoolgirls in Poland are laced leather sneakers or leather-like materials, on a flat plastic sole, while typical indoor shoes are lace-up sneakers on a rubber sole.

The footwear fitting to the feet of the examined children was tested using the Clevermess device (Clevermess $\mathrm{GmbH}$ ), which consisted of a toe limiter, heel stop, buckles to measure foot width, extension mounted on the back of the device, allowing measurements of shoes larger than size 31.

First, the length and width of the foot were measured. To measure the length, the child's foot was placed on the device so that the stops adhered closely to the heel and toes. During the measurement of the foot width, attention was paid that the clamps should be pressed against the width of the foot and were connected over its dorsal surface. The measurement results were automatically saved in the device's memory. Subsequently, the device was put into the shoe in order to measure the length and width of its interior. After 3 seconds from placing in the shoe, the device signaled the end of the measurement. After removing the scoop from the shoe, the result was on the screen, which contained information about the free space in the shoe (the functional length excess and the functional width excess).

When assessing footwear fitting in terms of length, the following criteria were adopted:

- too short footwear - when the functional length excess was less than $8 \mathrm{~mm}$,

- appropriate footwear - when the length excess was 8-12 mm,

- too long footwear - when the length excess was over $12 \mathrm{~mm}$ [13].

The following criteria were taken into account when assessing footwear fitting in terms of width:

- too narrow footwear - when the width excess was less than $1 \mathrm{~mm}$,

- appropriate footwear - when the width excess was 1-3 mm,

- too wide footwear - when the width excess was over $3 \mathrm{~mm}[13,14]$. 
In order to preserve the integrity of the research process, all the measurements were taken in the gym, in the morning, using the same measuring instruments operated by the authors. Girls were wearing their gymnastic uniforms. For the podoscopic examination, the girls were without shoes and socks, while for measuring the footwear fitting with Clevermess device, they put on socks. Procedures were carried out in accordance with Declaration of Helsinki for experiments involving humans. All participants and their parents or legal guardians received detailed information concerning the aim and methodology used in the study. The study was approved by the Local Ethics Committee of Rzeszow University (No. 3/12/2015).

Based on the gathered data, descriptive statistics were calculated. The analysis was carried out using the Pearson Chi-square test $\left(\chi^{2}\right)$. The results were considered statistically significant if the probability level of the test was lower than the predetermined significance level $p<0.05$. The Stat Soft STATISTICA software (version 13.1) was used to process the test results.

\section{RESULTS}

Table 1 includes descriptive statistics of the foot construction characteristics in the examined girls.

The data in Table 2 indicate the existence of statistically significant relationships between the frequency of varus deformity of the Vth toe of the right foot and the width fitting of the outdoor footwear $(p=0.027)$.

A more detailed analysis in Table 3 showed that the varus deformity of the Vth toe of the right foot is more often found in girls wearing too wide shoes (87.5\% of the respondents), and the least often in girls using shoes that are properly fitted (56.5\% of the respondents).

The results presented in Table 4 indicate the existence of statistically significant relationships between the length of the indoor footwear and the heel angle $(\gamma)$ of the left foot $(p=0.038)$.

Table 1. Descriptive statistics of structural features of the subjects' feet

\begin{tabular}{|c|c|c|c|c|c|c|}
\hline Feature & & $\overline{\mathrm{x}} \pm \mathrm{SD}$ & $\max -\min$ & $\mathrm{Q}_{25}$ & $\mathrm{Me}$ & $\mathrm{Q}_{75}$ \\
\hline \multirow{2}{*}{ Foot length [cm] } & rf & $19.54 \pm 1.16$ & $22.10-17.20$ & 18.70 & 19.45 & 20.40 \\
\hline & If & $19.54 \pm 1.17$ & $22.10-17.20$ & 18.70 & 19.50 & 20.40 \\
\hline \multirow{2}{*}{ Foot width $[\mathrm{cm}]$} & rf & $7.43 \pm 0.47$ & $8.90-6.50$ & 7.05 & 7.40 & 7.70 \\
\hline & If & $7.48 \pm 0.45$ & $8.50-6.50$ & 7.15 & 7.50 & 7.70 \\
\hline \multirow{2}{*}{ Clarke's angle $\left[{ }^{\circ}\right]$} & rf & $33.38 \pm 9.49$ & $50.00-11.00$ & 29.50 & 35.00 & 40.00 \\
\hline & If & $32.02 \pm 10.21$ & $49.00-8.00$ & 24.00 & 34.00 & 40.00 \\
\hline \multirow{2}{*}{ Heel angle $\gamma\left[{ }^{\circ}\right]$} & rf & $17.30 \pm 2.00$ & $23.00-13.00$ & 16.00 & 17.00 & 18.00 \\
\hline & If & $17.26 \pm 1.74$ & $21.00-13.00$ & 16.00 & 17.00 & 18.00 \\
\hline \multirow{2}{*}{ Hallux valgus angle $\alpha\left[^{\circ}\right]$} & rf & $5.42 \pm 4.47$ & $16.00-0.00$ & 0.50 & 5.00 & 8.00 \\
\hline & If & $5.57 \pm 4.09$ & $17.00-0.00$ & 3.00 & 5.00 & 8.00 \\
\hline \multirow{2}{*}{$\begin{array}{l}\text { The angle of the varus } \\
\text { deformity of the Vth toe } \beta\left[^{\circ}\right]\end{array}$} & rf & $13.69 \pm 5.20$ & $26.00-0.00$ & 10.00 & 14.00 & 17.00 \\
\hline & & $13.31 \pm 5.77$ & $27.00-0.00$ & 10.00 & 14.00 & 17.00 \\
\hline
\end{tabular}

rf, right foot; If, left foot 
Table. 2. Dependencies between the fitting of indoor and outdoor footwear and the construction of the examined girls' right feet

\begin{tabular}{lcc}
\multicolumn{1}{c}{ Pair of variables } & Chi-square test & $p$ \\
\hline Length of the outdoor footwear \& the medial longitudinal foot arch & $\chi^{2}(4)=2.54$ & 0.637 \\
Width of the outdoor footwear \& the medial longitudinal foot arch & $\chi^{2}(4)=5.24$ & 0.262 \\
Length of the indoor footwear \& the medial longitudinal foot arch & $\chi^{2}(4)=6.03$ & 0.196 \\
Width of the indoor footwear \& the medial longitudinal foot arch & $\chi^{2}(4)=4.34$ & 0.361 \\
Length of the outdoor footwear \& transverse foot arch & $\chi^{2}(4)=0.86$ & 0.929 \\
Width of the outdoor footwear \& transverse foot arch & $\chi^{2}(4)=7.41$ & 0.115 \\
Length of the indoor footwear \& transverse foot arch & $\chi^{2}(4)=1.49$ & 0.828 \\
Width of the indoor footwear \& transverse foot arch & $\chi^{2}(4)=4.31$ & 0.364 \\
Length of the outdoor footwear \& setting of the hallux & $\chi^{2}(2)=0.15$ & 0.924 \\
Width of the outdoor footwear \& setting of the hallux & $\chi^{2}(2)=0.51$ & 0.772 \\
Length of the indoor footwear \& setting of the hallux & $\chi^{2}(2)=0.94$ & 0.624 \\
Width of the indoor footwear \& setting of the hallux & $\chi^{2}(2)=5.25$ & 0.072 \\
Length of the outdoor footwear \& setting of the Vth toe & $\chi^{2}(2)=0.89$ & 0.638 \\
Width of the outdoor footwear \& setting of the Vth toe & $\chi^{2}(2)=7.18$ & $0.027 *$ \\
Length of the indoor footwear \& setting of the Vth toe & $\chi^{2}(2)=1.41$ & 0.494 \\
Width of the indoor footwear \& setting of the Vth toe & $\chi^{2}(2)=2.91$ & 0.232 \\
\hline * p<0.05 & &
\end{tabular}

Table 3. The prevalence of deformation of the Vth toe of the right foot, depending on the width of the used outdoor footwear

\begin{tabular}{|c|c|c|c|c|c|c|c|c|}
\hline \multirow{2}{*}{ Setting of the Vth toe } & \multicolumn{2}{|c|}{$\begin{array}{l}\text { Appropriate } \\
\text { footwear }\end{array}$} & \multicolumn{2}{|c|}{$\begin{array}{l}\text { Too wide } \\
\text { footwear }\end{array}$} & \multicolumn{2}{|c|}{$\begin{array}{l}\text { Too narrow } \\
\text { footwear }\end{array}$} & \multicolumn{2}{|c|}{ Total } \\
\hline & $\mathrm{n}$ & $\%$ & $\mathrm{n}$ & $\%$ & $\mathrm{n}$ & $\%$ & $n$ & $\%$ \\
\hline Normal setting & 10 & 43.5 & 4 & 12.5 & 10 & 22.2 & 24 & 24.0 \\
\hline The Vth toe varus deformity & 13 & 56.5 & 28 & 87.5 & 35 & 77.8 & 76 & 76.0 \\
\hline Chi-square test & \multicolumn{8}{|c|}{$\chi^{2}(2)=7.18 ; p=0.027^{*}$} \\
\hline
\end{tabular}

Table 4. Dependencies between the fitting of indoor and outdoor footwear and the construction of the examined girls' left feet

\begin{tabular}{llc}
\hline \multicolumn{1}{c}{ Pair of variables } & Chi-square test & $p$ \\
\hline Length of the outdoor footwear \& the medial longitudinal foot arch & $\chi^{2}(4)=2.17$ & 0.702 \\
Width of the outdoor footwear \& the medial longitudinal foot arch & $\chi^{2}(4)=7.63$ & 0.105 \\
Length of the indoor footwear \& the medial longitudinal foot arch & $\chi^{2}(4)=3.32$ & 0.504 \\
Width of the indoor footwear \& the medial longitudinal foot arch & $\chi^{2}(4)=6.85$ & 0.143 \\
Length of the outdoor footwear \& transverse foot arch & $\chi^{2}(2)=3.59$ & 0.463 \\
Width of the outdoor footwear \& transverse foot arch & $\chi^{2}(2)=5.34$ & 0.253 \\
Length of the indoor footwear \& transverse foot arch & $\chi^{2}(2)=10.10$ & $0.038 *$ \\
Width of the indoor footwear \& transverse foot arch & $\chi^{2}(2)=5.15$ & 0.271 \\
Length of the outdoor footwear \& setting of the hallux & $\chi^{2}(2)=1.32$ & 0.516 \\
Width of the outdoor footwear \& setting of the hallux & $\chi^{2}(2)=1.12$ & 0.569 \\
Length of the indoor footwear \& setting of the hallux & $\chi^{2}(2)=3.11$ & 0.210 \\
Width of the indoor footwear \& setting of the hallux & $\chi^{2}(2)=0.22$ & 0.892 \\
Length of the outdoor footwear \& setting of the Vth toe & $\chi^{2}(4)=1.87$ & 0.391 \\
Width of the outdoor footwear \& setting of the Vth toe & $\chi^{2}(4)=0.04$ & 0.979 \\
Length of the indoor footwear \& setting of the Vth toe & $\chi^{2}(4)=0.20$ & 0.901 \\
Width of the indoor footwear \& setting of the Vth toe & $\chi^{2}(4)=0.99$ & 0.609 \\
\hline * p<0.05 & &
\end{tabular}


A more detailed analysis in Table 5 showed that the left laterally hollowed feet were noted only in girls using too short shoes (9.3\% of the respondents). In turn, the prevalence of the lateral flat foot of the left foot was the highest in the case of the users of too long shoes (35.7\% of the respondents).

Table 5. The prevalence of deformation of the transverse arch of the left foot and the length of the indoor footwear used

\begin{tabular}{|c|c|c|c|c|c|c|c|c|}
\hline \multirow{2}{*}{ Transverse foot arch } & \multicolumn{2}{|c|}{$\begin{array}{l}\text { Appropriate } \\
\text { footwear }\end{array}$} & \multicolumn{2}{|c|}{$\begin{array}{l}\text { Too long } \\
\text { footwear }\end{array}$} & \multicolumn{2}{|c|}{$\begin{array}{l}\text { Too short } \\
\text { footwear }\end{array}$} & \multicolumn{2}{|c|}{ Total } \\
\hline & $\mathrm{n}$ & $\%$ & $n$ & $\%$ & $n$ & $\%$ & $n$ & $\%$ \\
\hline High arched foot & 0 & 0.0 & 0 & 0.0 & 4 & 9.3 & 4 & 4.0 \\
\hline Normal foot & 30 & 69.8 & 9 & 64.3 & 34 & 79.1 & 73 & 73.0 \\
\hline Flat foot & 13 & 30.2 & 5 & 35.7 & 5 & 11.6 & 23 & 23.0 \\
\hline Chi-square test & \multicolumn{8}{|c|}{$\chi^{2}(2)=10.10 ; p=0.038^{*}$} \\
\hline
\end{tabular}

$* \mathrm{p}<0.05$

\section{DISCUSSION}

In the literature, there are reports whose authors raise the issue of footwear fitting. Zhang et al. [20] observed disturbances in the formation of longitudinal arches of the feet in pre-school children living in the province of Fujian. These changes mostly concerned girls' feet and were related to wearing inadequately fitted footwear. Bari et al. [21] concluded that most of the examined 303 children aged 5-6 from Malaysia wore incorrectly fitted footwear. The authors consider the availability of only imported shoes on the Malaysian market, which are typical of the populations inhabiting the United States or the area of Great Britain. Also Naimah et al. [22] found that imported models work well on the feet of European children, while they are definitely inadequate for Malaysian children, as they are characterized by much smaller foot sizes compared to Europeans. Hettigama et al. [23], on the basis of surveys of school students in Sri Lanka aged 8 and 12, stated that the dynamics of the growth of longitudinal features, including the foot length indicates the necessity of frequent change of shoes, which primarily allows them to be correctly fitted to the current foot construction. The authors found that the awareness of the need to wear the correct footwear would counteract diseases and deformities of the feet. They emphasized the urgent need to design and manufacture ergonomic footwear and pointed to the need to adapt the range of footwear produced by companies to the individual needs of customers, including children in Sri Lanka. The precise selection of footwear should be based on accurate tests, taking into account both foot anatomy and the gait specificity. Schwarzkopf et al. [24] noted differences in the length of the right and left foot in $60 \%$ of the 235 surveyed residents of New York over 18 years of age. On this basis, they stressed the difficulty in choosing the right size of footwear. Klein et al. [25] assessed the quality of footwear worn by Austrian pre-school children aged 3 to 6.5. To measure the length of the inside of the shoe, the authors used a sliding measure. In the classification of results, they included a travel space of at least $10 \mathrm{~mm}$ (optimally $12 \mathrm{~mm}$ ) more than the length of the foot. Most of the children did not have indoor shoes, or they wore indoor shoes that were not adequately fitted and of worse quality than outdoor footwear. Only $23 \%$ of 858 studied children wore well-fitted outdoor footwear, and $9 \%$ had well-fitted indoor footwear. Teachers reported that in many cases these shoes were not exchanged throughout the school year. According to the authors, this may be partly due to the fact that parents pay less attention to the footwear that children wear at school than to the outdoor footwear. 
Knapik [13] verified the correctness of choosing the size of used and purchased footwear by parents of 500 school-aged children. For this purpose, in the shoe stores the author carried out direct measurements of the length of the feet, plantographic measurements of the angle of hallux valgus and varus deformity of the Vth toe, as well as the measurement of the inner length of the footwear in which the children came to the store and the inner length of the footwear purchased. In addition, a diagnostic survey was conducted on, among others, the influence of footwear on the health condition of feet and the self-assessment of the fitting of footwear used and purchased. In the analysis of the collected material, a functional surplus amounting to $10 \mathrm{~mm}$ was taken into account. The effect of wearing inappropriate footwear on the health condition of feet was found. The parents' relatively high awareness of the impact of inappropriate footwear on the condition of the feet was not confirmed by the degree of footwear fitting. Most of the respondents wore footwear equal to the length of the foot or too short ones. According to the author, the most disturbing fact was that a significant percentage of parents bought too short shoes for their children.

Our research is one of few papers in the field of footwear impact on foot formation in girls in early childhood. The obtained results indicate that in the case of the left foot, the incidence of transverse flat foot was the highest in girls wearing too long indoor shoes. This suggests that children with a wider forefoot wear longer shoes to avoid discomfort. It also points to the fact that in the production of footwear, which most often serves as indoor, the differences in the width of girls' feet are not taken into account.

The left laterally hollow feet were recorded only in girls using too short indoor footwear, and thus lacking free space, which is necessary for correct setting of the foot during movement or load. Due to the non-physiological setting of the foot in the shoe, muscle tension increases, which may lead to excessive arching of the foot and has a negative impact on its mobility and flexibility.

An equally important issue is width fitting of the footwear. Chaiwanichsiri et al. [26] pointed out that wearing too narrow shoes, especially in childhood, causes abnormal tension in the muscles and tendons of the feet, the formation of bunions and unsightly thickenings. Too narrow shoes compress the feet, hindering their natural development, as well as impede the work of the muscles. They cause distortion of the toes and stretching of the ligaments maintaining the transverse arch. In turn, wearing too wide shoes is the cause of instability during locomotion and resulting injuries.

Our research indicated the existence of statistically significant relationships between the prevalence of varus deformity of the Vth toe of the right foot and the width fitting of the outdoor footwear. This deformation was significantly more common in girls who wear too wide shoes, and least often in girls using shoes that are properly fitted. A comprehensive look at the data discussed above suggests that properly chosen footwear in terms of width favors the formation of normal foot architecture, but wearing too wide shoes may cause instability, resulting in adverse changes in the fifth toe setting.

The review of scientific publications and the results of own research indicate the need to pay attention to the fitting and condition of both indoor and outdoor footwear. The dynamic growth of children's feet makes it necessary to constantly monitor the condition of footwear. Doing so will allow for frequent replacement and thus reduce the frequency of foot deformities. It is worth 
emphasizing here that although children's shoes are intended for children, the parents usually buy them, who often, especially in the case of footwear bought for girls, are willing to follow fashion. Therefore, in many cases when choosing shoes, their primary purpose is no longer important, such as protection of feet against injuries and adverse weather conditions. It is also worth stressing that parents' decisions regarding the purchase of shoes are often a reaction to the producers' offer. Currently, in order to satisfy users' aesthetic needs, children's footwear is very often modeled on shoes for adults, which is why it is non-physiological and does not support the development of feet. Therefore, when buying shoes, it is particularly important to know how to select them, as well as to pay attention to the subjective feelings of children.

\section{CONCLUSIONS}

Children with a wider forefoot wear longer shoes, which is why there is a need to take into account differences in foot width in footwear production, which serves indoor. The use of too short footwear, without free space that is necessary for the proper setting of the foot during movement or load, is a factor leading to excessive lateral arching.

Wearing too wide shoes affects the formation of varus deformity of the Vth toe of the right foot.

\section{REFERENCES}

[1] Abledu JK, Abledu GK, Offei EB, Antwi EM. Determination of sex from footprint dimensions in a Ghanaian population. PLoS One. 2015;10(19):e0139891. https://doi.org/10.1371/journal.pone.0139891

[2] Deepashini H, Omar B, Paungmali A, Amaramalar N, Ohnmar H, Leonard J. An insight into the plantar pressure distribution of the foot in clinical practice: Narrative review. Pol Ann Med. 2014;21(1):51-56. https://doi.org/10.1016/j.poamed.2014.03.003

[3] Puszczalowska-Lizis E, Bujas P, Omorczyk J, Jandzis S, Zak M. Feet deformities are correlated with impaired balance and postural stability in seniors over 75. PLoS One. 2017;12(9):e0183227. https:// doi.org/10.1371/journal.pone.0183227

[4] Delgado-Abellán L, Aguado X, Jiménez-Ormeño E, Mecerreyes L, Alegre LM. Foot morphology in Spanish school children according to sex and age. Ergonomics. 2014;57(5):787-797. https://doi.org /10.1080/00140139.2014.895055

[5] Dinato RC, Ribeiro AP, Butugan MK, Pereira IL, Onodera AN, Sacco IC. Biomechanical variables and perception of comfort in running shoes with different cushioning technologies. J Sci Med Sport. 2015;18(1):93-97. https://doi.org/10.1016/j.jsams.2013.12.003

[6] Mauch M, Grau S, Krauss I, Maiwald C, Horstmann T. A new approach to children's footwear based on foot type classification. Ergonomics. 2009;52(8):999-1008. https://doi.org/10.1080/00140130902803549

[7] Zhang XL, Zhu XL. Biomechanical features of children's foot and design of children's shoes. J Beijing Sport Univ. 2010;33(6):57-61.

[8] Zhang D, Wang Y. Study on the influencing factors on comfort of children's shoes. J Bus Admin Res. 2017;6(2):40-45. https://doi.org/10.5430/jbar.v6n2p40

[9] Mei Q, Gu Y, Sun D, Fernandez J. How foot morphology changes influence shoe comfort and plantar pressure before and after long distance running? Acta Bioeng Biomech. 2018; 20(2):179-186.

[10] Wolf S, Simon J, Patikas D, Schuster W, Armbrust P, Döderlein L. Foot motion in children shoes: A comparison of barefoot walking with shod walking in conventional and flexible shoes. Gait Posture. 2008;27(1):51-59. https://doi.org/10.1016/j.gaitpost.2007.01.005

[11] Walther M, Herold D, Sinderhauf A, Morrison R. Children sport shoes - A systematic review of current literature. Foot Ankle Surg. 2008;14(4):180-189. https://doi.org/10.1016/j.fas.2008.04.001

[12] Wang XX, Chen SQ, Lin DY. Analysis of the relationship between the basic width and ball girth of children's feet. China Leather. 2014;24:118-125.

[13] Knapik H. The problem of the fitting of footwear used and purchased for children and youth in Poland. In: Design, materials, leather, clothing and footwear technology. Ed. M. Pawłowa. Radom University of Technology 2000, 156-165.

[14] Rajchel-Chyla B, Skrzyńska B, Janocha M, Gajewski R. The foot length changes due to age as well as load during ambulation and determination of the toe allowance. Prz Wlok. 2012;3:23-26.

[15] Chen KC, Yeh CJ, Kuo JF, Hsieh CL, Yang SF. Wang C.H., Footprint analysis of flatfoot in preschoolaged children. Eur J Pediatr. 2011;170(5):611-617. https://doi.org/10.1007/s00431-010-1330-4

[16] Okuda H, Juman S, Ueda A, Miki T, Shima M. Factors related to prevalence of hallux valgus in female university students: a cross-sectional study. J Epidemiol. 2014;24(3):200-208. https://doi.org/10.2188/ jea.JE20130110 
[17] Zhou J, Hlavacek P, Xu B, Chen W. Approach for measuring the angle of hallux valgus. Indian J Orthop. 2013;47(3):278-282. https://doi.org/10.4103/0019-5413.109875

[18] Pita-Fernández S, González-Martín C, Seoane-Pillado T, López-Calviño B, Pértega-Díaz S, Gil-Guillén V. Validity of footprint analysis to determine flatfoot using clinical diagnosis as the gold standard in a random sample aged 40 years and older. J Epidemiol. 2015;25 (2):148-154. https://doi.org/10.2188/ jea.JE20140082

[19] Puszczalowska-Lizis E, Zarzyczna P, Mikulakova W. Impact of footwear fitting on foot shape in primary schoolgirls. Acta Bioeng Biomech 2020; 22(1):119-126. https://doi.org/10.37190/ABB-01425-2019-02

[20] Zhang Z, Qiu L, Lin DY. Analysis of children's foot type and abnormal arch in Fujian province. China Leather. 2015;4:110-115.

[21] Bari SB, Othman M, Mohd Salleh N. Foot anthropometry for shoe design among preschool children in Malaysia. Pertanika J. Soc. Sci. Hum. 2010;18(1):69-79.

[22] Naimah MS, Mumtazah O, Shamsul Azahari ZB, Nurizan Y, Sharizal B. Development of clothing sizing system among children in Peninsula Malaysia. J Malays Cons. 2007;9:44-53.

[23] Hettigama IS, Punchihewa HK, Heenkenda NK. Ergonomic footwear for Sri Lankan primary schoolchildren: A review of the literature. Work. 2016;55(2):285-295. https://doi.org/10.3233/WOR162415

[24] Schwarzkopf R, Perretta DJ, Russell TA, Sheskier SC. Foot and shoe size mismatch in three different New York City populations. J Foot Ankle Surg. 2011; 50(4):391-394. https://doi.org/10.1053/j. jfas.2011.04.030

[25] Klein C, Groll-Knapp E, Kundi M, Kinz W. Increased hallux angle in children and its association with insufficient length of footwear: a community based cross-sectional study. BMC Musculoskelet Disord. 2009;10:159. https://doi.org/10.1186/1471-2474-10-159

[26] Chaiwanichsiri D, Tantisiriwat N, Janchai S. Proper shoe sizes for Thai elderly. Foot. 2008;18(4):186-191. https://doi.org/10.1016/j.foot.2008.05.001 